\title{
Proton Affinities of $N$-Heterocyclic Carbene Super Bases
}

\author{
Hao Chen, Dina R. Justes and R. Graham Cooks* \\ Department of Chemistry, Purdue University, West Lafayette, IN 47907 \\ cooks@purdue.edu
}

\section{Experimental}

Ionic liquid 1-ethyl-3-methyl-1H-imidazolium tetrafluoroborate and two reference super bases DBN and DBU were obtained from Aldrich (Milwaukee, WI). Other imidazolium salts were obtained from Strem Chemicals (Newburyport, MA) and used without further purification. Experiments were performed on a Finnigan TSQ7000 (Finnigan MAT, San Jose, CA) with an electrospray ionization (ESI) source. The applied high voltage was $4.5 \mathrm{kV}$ and the heated capillary temperature was $50{ }^{\circ} \mathrm{C}$. The cluster ion of interest was mass-selected using Q1 and dissociated in Q2 with argon (ca. $2.0 \mathrm{~m}$ Torr), and the resulting product ions were analyzed by scanning Q3 across the mass range of interest. Collision-induced dissociation measurements were made at 10, 15, 20, 40 and 50 $\mathrm{eV}$ collision energies. Average values are obtained from triplicate measurements each of 100 scans. 
Table 1S. Natural logarithm of product ion abundance ratios (lnR) for CID of the protonbound cluster ion with DBU at $10 \mathrm{eV}$ collision energy

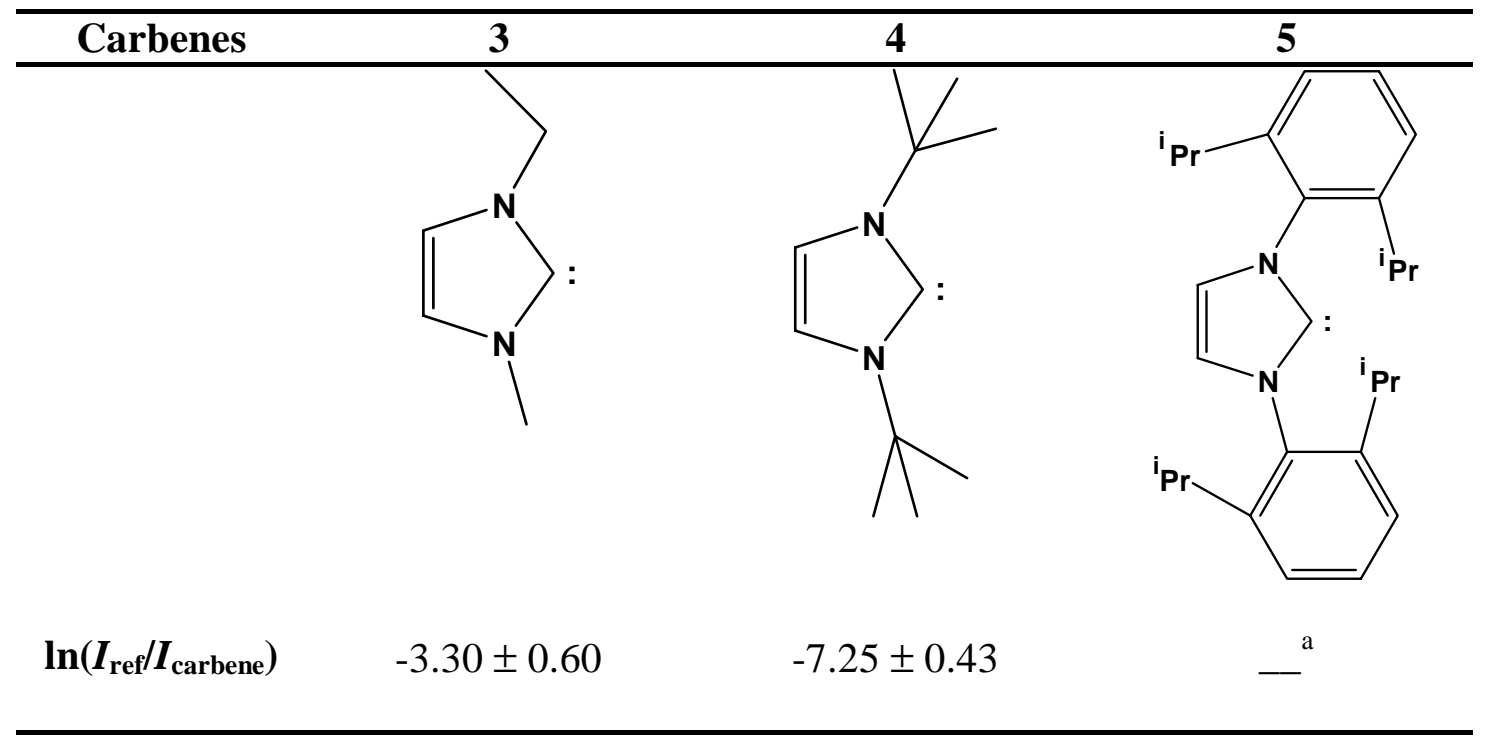

${ }^{\mathrm{a}} \mathrm{No}[\mathrm{DBU}+\mathrm{H}]^{+}$ion was observed in this case; the fragment ion is exclusively imidazolium ion 